\title{
ABO Blood Groups and Their Relationship with Coagulation Factor VIII in Healthy Adults
}

\author{
Afrina Binte Azad1*, Qazi Shamima Akhter², Mohammad Aminul Islam³, \\ Farzana Yeasmin Mukta ${ }^{4}$, Lily Afroz ${ }^{5}$, Khushbun Nahar Layla ${ }^{6}$, Tahmina Akter $^{2}$, \\ Shamanta Islam7 ${ }^{7}$ A. Z. M. Adnan8 \\ ${ }^{1}$ National Institute of Traumatology and Orthopaedics Rehabilitation, Dhaka, Bangladesh \\ ${ }^{2}$ Department of Physiology, Dhaka Medical College and Hospital, Dhaka, Bangladesh \\ ${ }^{3}$ Department of Orthopaedics, National Institute of Traumatology and Orthopaedics Rehabilitation, Dhaka, Bangladesh \\ ${ }^{4}$ Department of Cardiology, Kurmitola General Hospital, Dhaka, Bangladesh \\ ${ }^{5}$ Department of Physiology, Mymensingh Medical College and Hospital, Mymensingh, Bangladesh \\ ${ }^{6}$ Department of Physiology, Ibrahim Medical College and Hospital, Dhaka, Bangladesh \\ ${ }^{7}$ Bhairab Upazila Health Complex, Kishoreganj, Bangladesh \\ ${ }^{8}$ Department of Nephrology, Chattogram Medical College and Hospital, Chattogram, Bangladesh \\ Email: ^afrina04emc@gmail.com, shamimaqazi@yahoo.com, aminul39mmc@gmail.com, farzanayeasminmukta@gmail.com, \\ lilyafrozszmc@gmail.com, laylaluna7671@gmail.com, tahmina.runa.akter1@gmail.com, shamanta.bmc@gmail.com, \\ omon25@gmail.com
}

How to cite this paper: Azad, A.B., Akhter, Q.S., Islam, M.A., Mukta, F.Y., Afroz, L., Layla, K.N., Akter, T., Islam, S. and Adnan, A.Z.M. (2021) ABO Blood Groups and Their Relationship with Coagulation Factor VIII in Healthy Adults. Journal of Biosciences and Medicines, 9, 49-58.

https://doi.org/10.4236/jbm.2021.99005

Received: July 28, 2021

Accepted: September 6, 2021

Published: September 9, 2021

Copyright $\odot 2021$ by author(s) and Scientific Research Publishing Inc. This work is licensed under the Creative Commons Attribution International License (CC BY 4.0).

http://creativecommons.org/licenses/by/4.0/

(c) (i) Open Access

\begin{abstract}
Background: $\mathrm{ABO}$ blood group distribution defers with racial and geographic variations. They are related to diseases like cardiovascular diseases, cerebral thromboembolism. ABO blood group system may influence coagulation factor VIII which may increase the future risk of thrombosis. Aim: To assess the relation of $\mathrm{ABO}$ blood group with coagulation factor VIII in healthy adults. Material and Methods: A prospective type of analytical cross-sectional study was conducted in the Department of Physiology, Dhaka Medical College, Dhaka from July 2019 to June 2020. After obtaining ethical clearance, a total of 190 healthy adults were selected from different areas of Dhaka city based on inclusion and exclusion criteria, with ages ranging from 18 - 45 years. The subjects were interviewed and detailed history regarding personal, family, medical and drug were taken. Prior to sample collection, informed written consent was taken from the participants. Individuals of blood group $A$ were selected as group $A$, blood group $B$ as group $B$, blood group $A B$ as group $A B$ and blood group $\mathrm{O}$ as group $\mathrm{O}$. Coagulation factor VIII was measured in the Department of Hematology and BMT Unit, Dhaka Medical College Hospital, Dhaka. Blood grouping was done in the Department of Physiology, Dhaka Medical College, Dhaka. Statistical Analysis: For statistical analysis, ONE
\end{abstract}


way ANOVA followed by Bonferroni test were considered using SPSS 25.0 version. Results: In this study, blood group B was most common (33.2\%). Coagulation factor VIII was significantly higher $(p<0.001)$ in blood group A $(105.76 \% \pm 11.82 \%), \mathrm{B}(112.00 \% \pm 15.02 \%), \mathrm{AB}(109.80 \% \pm 11.93 \%)$ than blood group $\mathrm{O}(82.00 \% \pm 12.86 \%)$. No significant difference was observed among $\mathrm{A}, \mathrm{B}$ and $\mathrm{AB}$ blood groups regarding coagulation factor VIII. Conclusions: It can be concluded that blood group $A, B, A B$ individuals may have more chance of thrombosis due to significantly higher coagulation factor VIII than blood group $\mathrm{O}$ individuals.

\section{Keywords}

ABO Blood Group, Coagulation Factor VIII, Healthy Adults

\section{Introduction}

ABO blood group was discovered by Karl Landsteiner in 1900. It was the landmark for the modern practice of transfusion medicine [1]. The incidence of ABO and $\mathrm{Rh}$ blood groups varies markedly with geographic and racial variations. In Caucasians of America, the predominant blood group is group O (45\%) followed by group A (41\%), B (10\%) and AB (4\%). Native American Indians belong almost to blood group $\mathrm{O}$. Among western Europeans, group $\mathrm{O}$ occurs in the highest frequency (46\%) followed by group A (42\%), B (9\%) and AB (3\%). In Eastern Europe, the predominant blood group is group B (40\%) [2]. In Australia and Britain, the commonest blood groups are group $\mathrm{O}$ and $\mathrm{A}$ followed by group $\mathrm{B}$ and $\mathrm{AB}$. In Indo-Pak sub-continent, group $\mathrm{B}$ and $\mathrm{O}$ occur in the highest frequency [3]. In Bangladesh, the commonest blood group is blood group B (34.4\%) followed by group $\mathrm{O}(30.4 \%), \mathrm{A}(26.7 \%)$ and $\mathrm{AB}(8.6 \%)$. The distribution of $\mathrm{Rh}$-positive blood group is $97.4 \%$ and $\mathrm{Rh}$-negative blood is $2.6 \%$ [4].

Determination of blood group is very essential as it plays an important role in genetics, blood transfusion, forensic medicine and may be related to diseases like duodenal ulcer, diabetes mellitus, urinary tract infection, $\mathrm{Rh}$ incompatibility and $\mathrm{ABO}$ incompatibility [5]. Blood group $\mathrm{O}$ has a strong association with duodenal ulcers [6].

Von Willebrand factor is a large glycoprotein which is synthesized by WeibelPalade bodies in the endothelial cells and alpha granules of megakaryocytes [7]. It is involved in hemostasis. Von Willebrand factor has two major roles in hemostasis. First, it helps in platelet adhesion and platelet aggregation. Second, Von Willebrand factor is the specific carrier of factor VIII in plasma. It protects factor VIII from proteolytic degradation and prolonging its half-life in circulation. Von Willebrand factor effectively localize factor VIII at the site of vascular injury [8].

ABO blood groups have a relation with plasma von Willebrand factor and factor VIII. Blood group O individuals have 25\% lower von Willebrand factor 
levels than non-O (A, B, AB) blood group individuals. Among non-O individuals, the $\mathrm{AB}$ group has the highest von Willebrand factor level, followed by blood group $\mathrm{B}$ and $\mathrm{A}$ individuals. Individuals with non-O blood groups show a significantly higher risk of thrombosis than blood group $\mathrm{O}$ due to increased von Willebrand factor and factor VIII [9]. Gallinaro et al. (2008) observed less von Willebrand factor in blood group $\mathrm{O}$ due to faster hepatic clearance of von Willebrand factor leading to shorter plasma half-life of it than non-O blood groups [10].

Some studies have shown the influence of $\mathrm{ABO}$ blood groups on plasma coagulation factor VIII in different populations. They found that mean factor VIII level was significantly higher in blood group $\mathrm{A}, \mathrm{B}$ and $\mathrm{AB}$ than blood group $\mathrm{O}$ individuals [11] [12] [13]. Ohira et al. (2007) carried out a study on ABO blood groups and the incidence of Venous Thromboembolism (VTE). They showed factor VIII was significantly higher in patients with VTE than participants free from VTE. They also observed significantly higher level of factor VIII in non-O blood group individuals than blood group $\mathrm{O}$. So, individuals with non-O blood groups may have more chance of thrombosis [14].

The present study was undertaken to assess the relation of $\mathrm{ABO}$ blood groups with coagulation factor VIII in healthy adults and to identify those blood groups which may have more chance of thrombotic diseases. This study also aimed to bring awareness to prevent thrombotic diseases related morbidity.

\section{Material and Methods}

This prospective type of analytical cross sectional study was carried out in the Department of Physiology, Dhaka Medical College, Dhaka from July 2019 to June 2020. A total of 190 Bangladeshi healthy adult male and female, aged 18 45 years were selected from different areas of Dhaka city for this study.

1) Study design: Prospective type of observational cross sectional study. It was analytical study and no follow up had done.

2) Study location: Department of Physiology, Dhaka Medical College and Hospital, Dhaka.

3) Study duration: July 2019 to June 2020 .

4) Sample size: 190 healthy adults.

5) Sample size calculation: The sample size was estimated on the basis of the difference between two means from previous study. We assumed that the power of the study was $80 \%$ and the level of significance was $5 \%$. The sample size actually obtained for this study was 30 healthy adults for each group (Group A, Group B, Group AB and Group O). We planned to include study subjects until fulfillment of minimum 30 subjects in each group.

6) Subjects \& selection method: Sample size was divided into four groups on the basis of $\mathrm{ABO}$ blood groups.

Group A: 45 healthy adults of blood group A.

Group B: 63 healthy adults of blood group B. 
Group AB: 30 healthy adults of blood group AB.

Group O: 52 healthy adults of blood group O.

7) Inclusion criteria

- Age: 18 - 45 years.

- Gender: Male and Female.

- BMI: 18.5 - 24.9.

- Ethnicity: Bengali.

\section{8) Exclusion criteria}

- History of blood coagulation disorders.

- Current history of taking anticoagulant, oral contraceptive pill.

- Pregnancy and lactation.

- Presence of any pathological condition such as thromboembolic events, hypertension, diabetes mellitus, anaemia, acute infection, chronic inflammatory disorders, hyperlipidemia, liver disease, renal disease, cerebrovascular disease, psychiatric illness, malignancy.

- Smoker.

- Prolonged immobilization, paralyzed.

\section{9) Procedure methodology}

The research work was carried out after obtaining ethical clearance from Research Review Committee of the Department of Physiology and Ethical Review Committee of Dhaka Medical College, Dhaka. Subjects from different areas of Dhaka city were contacted either by phone or in person and details of the study procedure, the nature, purpose and benefit of the study was explained to each subject. They were asked for their voluntary participation. Subjects who were interested to take part in the study were requested to attend the Department of Physiology, Dhaka Medical College, Dhaka, in fasting state. When they came, they were interviewed and detail history regarding personal, family, medical and drug history were taken. Anthropometric measurements of the subjects were done and blood pressure was measured. All the information was recorded in a prefixed data collection form. Prior to blood sample collection, informed written consent was taken from the participants. Coagulation factor VIII was estimated in the Department of Haematology \& BMT Unit, Dhaka Medical College Hospital, Dhaka, by using Sysmex fully automated coagulation analyzer machine. Blood grouping was done in the Department of Physiology, Dhaka Medical College, Dhaka, on the basis of presence or the absence of agglutination by slide method. Subjects who were unable to come to Dhaka Medical College, their blood samples were collected from their respective work station or from their home. These blood samples were carried in a cool box to the respective department of Dhaka Medical College Hospital, Dhaka for investigations. Study subjects were grouped into four groups on the basis of blood grouping. Blood sample collection was continued until fulfillment of minimum 30 subjects in each group. To fulfill minimum 30 subjects in each group, equal number of study subjects could not be maintained. Blood samples were collected from total 196 subjects. Among them, two subjects were excluded due to higher SGPT level 
above normal range, two subjects were excluded due to higher blood glucose level above normal range, one subject was excluded due to higher serum cholesterol level above normal range and one subject was excluded due to lower haemoglobin concentration level below normal range. At the end, total 190 subjects were included in this study. Out of them, 45 study subjects were included in group A, 63 study subjects were included in group B, 30 study subjects were included in group $A B$ and 52 study subjects were included in group $\mathrm{O}$.

\section{0) Statistical analysis}

All the parameters were expressed as mean \pm SD (standard deviation) and range. One way ANOVA followed by Bonferroni test was performed to compare between groups. $p$ value $<0.05$ was accepted as level of significance. Statistical analysis was performed by using a computer based statistical program SPSS (Statistical Package for Social Science) version 25.0.

\section{Results and Discussion}

Table 1 and Figure 1 show, the number and percent distribution of $A B O$ blood groups of the study subjects. ABO blood groups revealed that group B was predominant with $33.2 \%$, followed by group O with $27.4 \%$, group A with $23.7 \%$ and

Table 1. Blood group distribution of the subjects $(\mathrm{N}=190)$.

\begin{tabular}{ccc}
\hline Blood groups & Number & Frequency \\
\hline A & 45 & Percent 23.7 \\
B & 63 & Percent 33.2 \\
AB & 30 & Percent 15.8 \\
O & 52 & Percent 27.4 \\
Total & 190 & Percent 100 \\
\hline
\end{tabular}

$\mathrm{N}=$ Total number of subjects

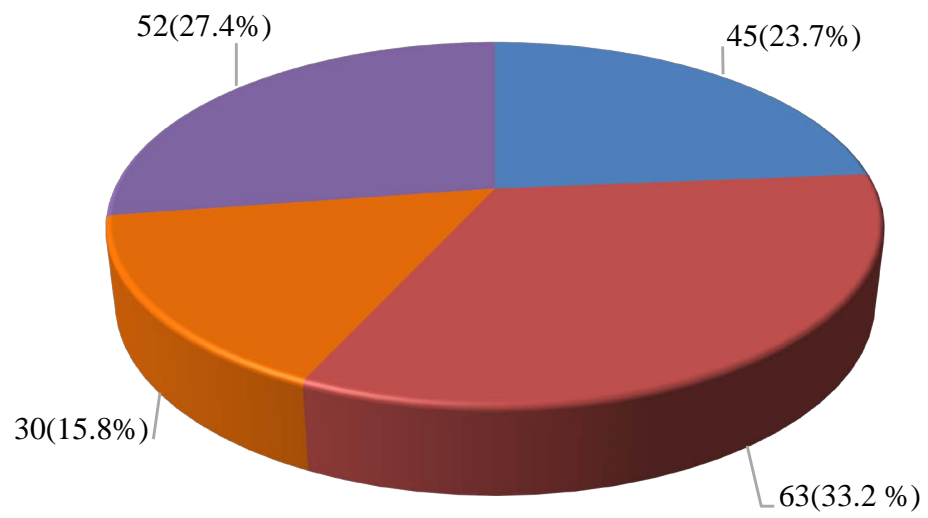

回A 回

Figure 1. Distribution of study subjects according to blood groups $(\mathrm{N}=190) . \mathrm{N}$ : Total number of subjects; A: Blood group A; B: Blood group B; AB: Blood group AB; O: Blood group O. 
group $\mathrm{AB}$ with $15.8 \%$. Almost similar types of results were observed by different researchers [3] [5] [15].

On the other hand, some disagreements observed by various studies which might be due racial and geographic variation. Some researcher found that blood group $\mathrm{O}$ was the predominant blood group followed by blood group A, B and $\mathrm{AB}$ [11] [14] [16]. Agrawal et al. (2014) observed that blood group $O$ was in highest frequency followed by blood group B, A and AB [17]. Choi et al. (2014) showed that blood group A was the commonest blood group followed by blood group $\mathrm{B}, \mathrm{O}$ and $\mathrm{AB}[13]$.

Table 2 and Figure 2 show, higher level of mean coagulation factor VIII in blood group B individuals (112.00\% $\pm 15.02 \%)$ followed by group AB $(109.80 \%$ $\pm 11.93 \%), \mathrm{A}(105.76 \% \pm 11.82 \%)$ and $\mathrm{O}(82.00 \% \pm 12.86 \%)$. The mean differences among the groups were statistically significant $(p<0.001)$. The mean difference between group $\mathrm{A}$ and $\mathrm{O}, \mathrm{B}$ and $\mathrm{O}, \mathrm{AB}$ and $\mathrm{O}$ was also statistically significant $(p<0.001)$. No significant difference in coagulation factor VIII level among group $\mathrm{A}, \mathrm{B}$ and $\mathrm{AB}$. Almost similar types of results were observed by different researchers [14] [18] [19].

Blood group A, B, AB individuals have additional carbohydrate to the terminal carbohydrate of peripheral core of the $\mathrm{H}$ substance (precursor antigen). When an additional carbohydrate is added by $\mathrm{N}$-acetyl-galactosamine, blood group $\mathrm{A}$ is produced. When an additional carbohydrate is added by the galactose transferase, blood group $B$ is produced. No carbohydrate is added to the $\mathrm{H}$ substance due to lack of transferase enzyme, produce blood group O. Von Willebrand factor

Table 2. Coagulation factor VIII of the study subjects in different groups $(\mathrm{N}=190)$.

\begin{tabular}{ccccc}
\hline Parameter & \multicolumn{4}{c}{ Groups } \\
& $\begin{array}{c}\text { Group A } \\
\left(\mathrm{n}_{1}=45\right)\end{array}$ & $\begin{array}{c}\text { Group B } \\
\left(\mathrm{n}_{2}=63\right)\end{array}$ & $\begin{array}{c}\text { Group AB } \\
\left(\mathrm{n}_{3}=30\right)\end{array}$ & $\begin{array}{c}\text { Group O } \\
\left(\mathrm{n}_{4}=52\right)\end{array}$ \\
\hline Coagulation factor VIII (\%) & $105.76 \pm 11.82$ & $112.00 \pm 15.02$ & $109.80 \pm 11.93$ & $82.00 \pm 12.86$ \\
\hline Statistical analysis & \multicolumn{2}{c}{$p$-value } \\
\hline Groups & Coagulation factor VIII \\
\hline A vs B vs AB vs O & $<0.001^{*}$ \\
A vs B & $0.101^{\mathrm{NS}}$ \\
A vs AB & $1.000^{\mathrm{NS}}$ \\
A vs O & $<0.001^{*}$ \\
B vs AB & $1.000^{\mathrm{NS}}$ \\
B vs O & $<0.001^{*}$ \\
AB vs O & $<0.001^{*}$ & \\
\hline
\end{tabular}

Results were expressed as Mean \pm SD. One way ANOVA followed by Bonferroni test was performed to compare between groups. $\mathrm{N}$ : Total number of subjects; $\mathrm{n}_{1}$ : number of subjects in group $\mathrm{A} ; \mathrm{n}_{2}$ : number of subjects in group $B ; n_{3}$ : number of subjects in group $A B ; n_{4}$ : number of subjects in group $O$. The test of significance was calculated for all comparisons and $p$ value $<0.05$ was accepted as level of significance. ${ }^{\text {NS not }}$ significant, *significant. Group A: blood group A; Group B: blood group B; Group AB: blood group AB; Group O: blood group O. 


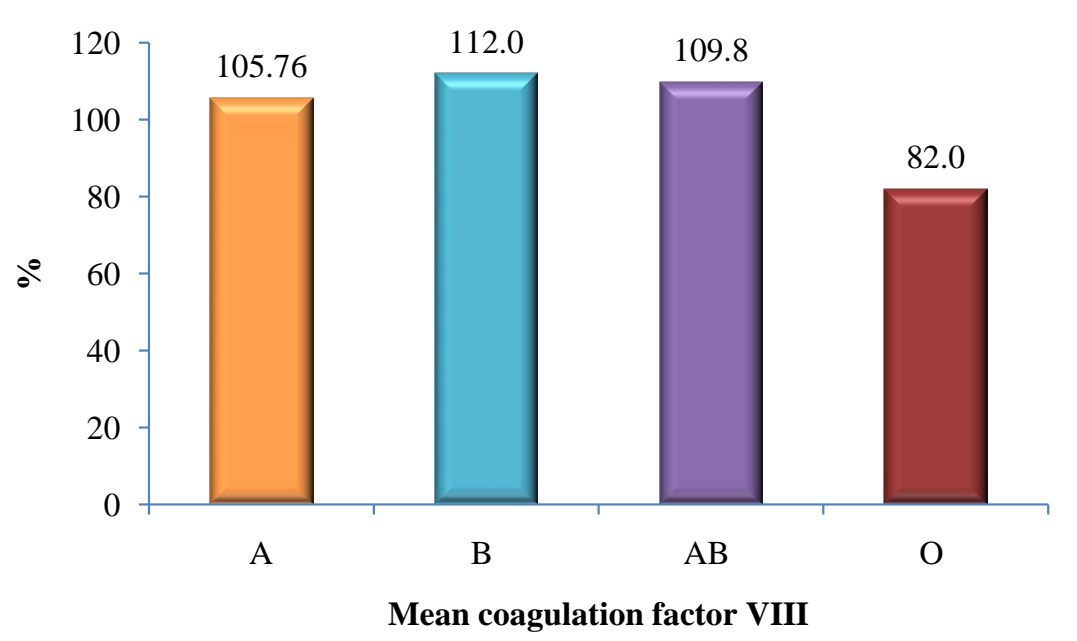

Figure 2. Mean coagulation factor VIII of the study subjects in different groups $(\mathrm{N}=$ 190). N: Total number of subjects; A: Blood group A; B: Blood group B; AB: Blood group AB; O: Blood group O.

is a large glycoprotein which is synthesized by Weibel-Palade bodies in the endothelial cells and alpha granules of megakaryocytes. Lowest plasma Von Willebrand factor level is present in genotype $\mathrm{OO}$ individuals (Blood group $\mathrm{O}$ ) due to lack of additional terminal sugar. Plasma Von Willebrand factor is proteolized by metalloprotease enzyme ADAMTS13. Proteolysis is faster for group O Von Willebrand factor than group $A, B, A B$ Von Willebrand factor. So blood group $A, B$ and $A B$ have more von Willebrand factor than blood group $O$. Von Willebrand factor is the specific carrier of factor VIII in plasma. It protects factor VIII from proteolytic degradation and prolonging its half-life in circulation. Thus von Willebrand factor protects factor VIII from proteolytic degradation and prolonging its plasma half-life in $\mathrm{A}, \mathrm{B}, \mathrm{AB}$ blood groups. This might be the cause of increased coagulation factor VIII level in blood group A, B and AB [7] [8] [11].

On the other hand, Albanez et al. (2016) found no significant difference in coagulation factor VIII level among ABO blood groups. They selected study subjects aged $1-17$ years. They suggested that, the effect of $A B O$ blood group on von Willebrand factor was limited in young age. Young age group might be the reason of contrary of the findings from present study [20]. Another research showed that factor VIII level was significantly higher in blood group A than blood group $\mathrm{B}, \mathrm{AB}$ and $\mathrm{O}$. Factor VIII level was significantly higher in blood group $B$ than blood group $A B$ and $O$. No significant difference was found between blood group $\mathrm{AB}$ and $\mathrm{O}$ in case of factor VIII level. This disagreement in findings might have occurred due to variation of von Willebrand factor in different races [21]. Loganathan et al. (2019) found no significant difference in factor VIII among blood group A, B, AB and O. They estimated factor VIII from fresh frozen plasma. That might be the cause of disagreement in findings [22]. Rejto et al. (2020) observed no significant difference among ABO blood groups in case of coagulation factor VIII. They include non severe haemophilia patients 
as study subjects. This might be the reason of contrary in findings from present study [23].

\section{Conclusion}

After analyzing the results of the study, it can be concluded that blood group $B$ is the most common (33.2\%) among the study subjects. Blood group A, B, AB individuals may have more chance of thrombosis due to significantly higher coagulation factor VIII than blood group O in this study.

\section{Acknowledgements}

The authors acknowledge the Department of Haematology \& BMT Unit, Dhaka Medical College Hospital, Dhaka, for their kind cooperation.

\section{Conflicts of Interest}

The authors declare no conflicts of interest regarding the publication of this paper.

\section{References}

[1] Schwarz, H.P. and Dorner, F. (2003) Karl Landsteiner and His Major Contributions to Haematology. British Journal of Haematology, 121, 556-565. https://doi.org/10.1046/j.1365-2141.2003.04295.X

[2] Pramanik, T. and Pramanik, S. (2000) Distribution of ABO and Rh Blood Groups in Nepalese Medical Students: A Report. Eastern Mediterranean Health Journal, 6, 156-158.

[3] Sultana, R., Rahman, Z., Helali, A.M., Yousuf, R., Mustafa, S., Salam, A. and Haque, M. (2013) Study of ABO and RH-D Blood Groups among the Common People of Bangladesh. International Journal of Pharmacy and Pharmaceutical Sciences, 5, 814-816.

[4] Dipta, T.F., Iqbal, M.R., Hossain, A.Z., Rahman, M.T. and Chowdhury, S. (2011) Distribution of Phenotypic and Genotypic Abo And Rhesus Blood Groups among Bangladeshi Population. Ibrahim Medical College Journal, 5, 59-62.

https://doi.org/10.3329/imcj.v5i2.10101

[5] Dibby, H.J. (2014) Blood Groups Distribution \& Its Relationship with Bleeding Time and Clotting Time. AL-Qadisiya Medical Journal, 10, 164-167.

[6] Akhtar, M.N., Butt, A.R., Tayyib, M. and Tasneem, T. (2003) ABO Blood Group in Patients with Peptic Ulcer Disease: Association with Secretor Status. Annals of King Edward Medical University, 9, 238-240. https://doi.org/10.21649/akemu.v9i3.1351

[7] Thenmozhi, S., Neelambikai, N. and Aruna P. (2013) Comparison of Bleeding Time and Clotting Time in different ABO Blood Groups. National Journal of Physiology, 1, 19-24.

[8] Franchini, M., Capra, F., Targher, G., Montagnana, M. and Lippi, G. (2007) Relationship between ABO Blood Group and von Willebrand Factor Levels: From Biology to Clinical Implications. Thrombosis Journal, 5, Article No. 14. https://doi.org/10.1186/1477-9560-5-14

[9] Franchini, M. and Mannucei, P.M. (2014) ABO Blood Group and Thromboyic Vascular Disease. Thrombosis and Haemostasis, 112, 1103-1109. 
https://doi.org/10.1160/th14-05-0457

[10] Gallinaro, L., Cattini, M.G., Sztukowska, M., Padrini, R., Sartorello, F., Pontara, E., Bertomoro, A., Daidone V., Pagnan, A. and Casonato, A. (2008) A Shorter Von Willebrand Factor Survival in O Blood Group Subjects Explains How ABO Determinants Influence Plasma Von Willebrand Factor. Blood, 111, 3540-3545. https://doi.org/10.1182/blood-2007-11-122945

[11] Wang, Z., Dou, M., Du, X., Ma, L., Sun, P., Cao, H., Ye, S., Jiang, P., Liu, F., Lin, F., Zhang, R. and Li, C. (2017) Influences of ABO Blood Group, Age and Gender on Plasma Coagulation Factor VIII, Fibrinogen, Von Willebrand Factor and ADAMTS13 Levels in a Chinese Population. PeerJ, 5, Article No. e3156.

https://doi.org/10.7717/peerj.3156

[12] Kremers, R.M.W., Mohamed, A.B.O., Pelkmans, L., Hindawi, S., Hemker, H.C., Laat, H.B., Husken, D. and Dieri, R.A. (2015) Thrombin Generating Capacity and Phenotypic Association in ABO Blood Groups. PLOS ONE, 10, e0141491. https://doi.org/10.1371/journal.pone.0141491

[13] Choi, Q., Kim, J.E., Kim, S.Y., Kyou, S.H. and Kim, H.K. (2014) Influence of ABO Type on Global Coagulation Assay Results: Effect of Coagulation Factor VIII. Clinical Chemistry and Laboratory Medicine, 53, 1425-1432. https://doi.org/10.1515/cclm-2014-0909

[14] Ohira, T., Cushman, M., Tsai, M.Y., Zhang, Y., Heckbert, S.R., Zakai, N.A., Rosamond, W.D. and Falsom, A.R. (2007) ABO Blood Group, Other Risk Factors and Incidence of Venous Thromboembolism: The Longitudinal Investigation of Thromboembolism Etiology (LITE). Journal of Thrombosis and Haemostasis, 5, 1455-1461. https://doi.org/10.1111/j.1538-7836.2007.02579.x

[15] Iqbal, M., Niazi, A. and Tahir, M. (2009) Frequency of ABO and Rh Blood Groups in Healthy Donors. Journal of Rawalpindi Medical College, 13, 92-94.

[16] Okeye, C.O., Okoro, U.S. and Babatunde, A. (2018) Variations in Activated Partial Thromboplastin Time and Prothrombin Time in Individuals of A, B, AB and O Blood Groups. Iraqi Journal of Hematology, 7, 85-89.

https://doi.org/10.4103/ijh.ijh 1118

[17] Agrawal, A., Tiwari, A.K., Mehta, N., Bhattacharya, P., Wankhede, R., Tulsiani, S. and Kamath, S. (2014) ABO and Rh (D) Group Distribution and Gene Frequency; The First Multicentric Study in India. Asian Journal of Transfusion Science, 8, 121-125. https://doi.org/10.4103/0973-6247.137452

[18] Song, J., Chen, F., Campos, M., Bolgiano, D., Houck, K., Chambless, L.E., Wu, K.K., Folsom,A.R., Couper, D., Boerwinkle, E. and Dong, J. (2015) Quantitative Influence of ABO Blood Groups on Factor VIII and Its Ratio to von Willebrand Factor, Novel Observations from an ARIC Study of 11,673 Subjects. PLoS ONE, 10, e0132626. https://doi.org/10.1371/journal.pone.0132626

[19] Zakai, N.A., Judd, S.E., Alexander, K., Mcclure, L.A., Kissela, B.M., Howard, G. and Cushman, M. (2014) ABO Blood Type and Stroke Risk: The Reasons for Geographic And Racial Differences in Stroke Study. Journal of Thrombosis and Haemostasis, 12, 564-570. https://doi.org/10.1111/jth.12507

[20] Albanez, S., Ogiwara, K., Michels, A., Hopman, W., Grabell, J., James, P. and Lillicrap, D. (2016) Aging and ABO Blood Type Influence Von Willebrand Factor and Factor VIII Levels through Interrelated Mechanisms. Journal of Thrombosis and Haemostasis, 14, 953-963. https://doi.org/10.1111/jth.13294

[21] Kabir, K., Hosseini, H., Zargar, M.J., Mandeh, Z., Amrollahi, F., Farahmandian, N. and Bahreini, E. (2019) The Effect of Incubation Time on the Activity and Stability of Factor VIII during the Preparation Process. International Journal of Medical La- 
boratory, 6, 199-206. https://doi.org/10.18502/ijml.v6i3.1401

[22] Loganathan, R., Kulkarni, R.G., Kar, R., Abhishekh, B. and Basu, D. (2019) Assessment and Association of Coagulation Factor (FVIII and Fibrinogen) with the Mode of Collection and Storage of Fresh Frozen Plasma. Global Journal of Transfusion Medicine, 4, 204-207. https://doi.org/10.4103/GJTM.GJTM 4119

[23] Rejto, J., Konigsbrugge, O., Grilz, E., Hofer, S., Mauracher, L., Gabler, C., Schuster, G., Feistritzer, C., Sunder-Plabmann, R., Quehenberger, P., Gebhart, J., Ay, C. and Pabinger, I. (2020) Influence of Blood Group, Von Willebrand Factor Levels, and Age on Factor VIII Levels in Non-Severe Haemophilia A. Journal of Thrombosis and Haemostasis, 18, 1081-1086. https://doi.org/10.1111/jth.14770 